\title{
Prion Strain Interactions Are Highly Selective
}

\author{
K. Peter R. Nilsson, ${ }^{1}$ Shivanjali Joshi-Barr, ${ }^{2,3}$ Olivia Winson, ${ }^{2,3}$ and Christina J. Sigurdson ${ }^{2,3,4}$ \\ ${ }^{1}$ Department of Physics, Chemistry, and Biology, Linköping University, SE-581 83 Linköping, Sweden, Departments of ${ }^{2}$ Pathology and ${ }^{3}$ Medicine, \\ University of California, San Diego, La Jolla, California 92093, and ${ }^{4}$ Department of Pathology, Immunology, and Microbiology, University of California, \\ Davis, California 95616
}

Various misfolded and aggregated neuronal proteins commonly coexist in neurodegenerative disease, but whether the proteins coaggregate and alter the disease pathogenesis is unclear. Here we used mixtures of distinct prion strains, which are believed to differ in conformation, to test the hypothesis that two different aggregates interact and change the disease in vivo. We tracked two prion strains in mice histopathologically and biochemically, as well as by spectral analysis of plaque-bound PTAA (polythiophene acetic acid), a conformation-sensitive fluorescent amyloid ligand. We found that prion strains interacted in a highly selective and strain-specific manner, with (1) no interaction, (2) hybrid plaque formation, or (3) blockage of one strain by a second (interference). The hybrid plaques were maintained on additional passage in vivo and each strain seemed to maintain its original conformational properties, suggesting that one strain served only as a scaffold for aggregation of the second strain. These findings not only further our understanding of prion strain interactions but also directly demonstrate interactions that may occur in other protein aggregate mixtures.

\section{Introduction}

Neurodegenerative diseases are progressive and debilitating disorders that commonly reveal the cooccurrence of multiple neuronal protein aggregates, such as amyloid- $\beta(\mathrm{A} \beta)$ and $\alpha$-synuclein (Selikhova et al., 2009), A $\beta$ and tau (Small and Duff, 2008), and A $\beta$ and misfolded prion protein, $\operatorname{PrP}^{\mathrm{Sc}}$ (Muramoto et al., 1992; Debatin et al., 2008; Ghoshal et al., 2009). Tau and $\alpha$-synuclein not only associate (Schmidt et al., 1996; Marui et al., 2000) but are also synergistic and promote the polymerization of each other into fibrils (Giasson et al., 2003). Similarly, oligomers of $A \beta$ and $\alpha$-synuclein form hybrid aggregates (Tsigelny et al., 2008) and A $\beta$ promotes $\alpha$-synuclein aggregation (Masliah et al., 2001). A $\beta$ aggregates also accelerate prion disease onset in mice (Morales et al., 2010).

In naturally occurring prion disease, multiple biochemically and histologically distinct subtypes can coexist within an individual. In sporadic Creutzfeldt-Jakob disease (sCJD), two subtypes were found to reside in 30-50\% of cases (Puoti et al., 1999; Polymenidou et al., 2005; Uro-Coste et al., 2008; Cali et al., 2009).

Prion infection offers an interesting model for investigating protein aggregate interactions since mammalian prion strains are believed to exist in distinct, stably propagating conformations. Prions catalyze their own propagation by recruiting and converting the nor-

Received May 11, 2010; revised July 12, 2010; accepted July 20, 2010.

This study was supported by National Institutes of Health Grants NS055116 and U54Al065359 (C.J.S.), the National Prion Research Program (C.J.S.), the Swedish Foundation for Strategic Research (K.P.R.N.), the European Union FP7 HEALTH (Project LUPAS) (K.P.R.N.), Institutional Grants for Younger Researchers from the Swedish Foundation for International Cooperation in Research and Higher Education (C.J.S., K.P.R.N.), and The Knut and Alice Wallenberg Foundation (K.P.R.N.). We thank Ilan Margalith for his excellent technical assistance with the spectra analysis. We also thank our histopathology and animal care staff for technical support, and Drs. Subhojit Roy, Steve Wagner, and Per Hammarström for discussion and reading of this manuscript. We are grateful to Dr. Adriano Aguzzi for generously providing the anti-PrP antibodies.

Correspondence should be addressed to Christina J. Sigurdson, Department of Pathology, University of California, San Diego, 9500 Gilman Drive, La Jolla, CA 92093. E-mail: csigurdson@ucsd.edu.

DOl:10.1523/JNEUROSCI.2417-10.2010

Copyright $\odot 2010$ the authors $\quad 0270-6474 / 10 / 3012094-10 \$ 15.00 / 0$ mal prion protein, $\operatorname{PrP}^{\mathrm{C}}$, into additional $\operatorname{PrP}^{\mathrm{Sc}}$ (Prusiner, 1982). Strains have different proteinase $\mathrm{K}(\mathrm{PK})$-resistant $\mathrm{PrP}^{\mathrm{Sc}}$ core sizes (Bessen and Marsh, 1992; Polymenidou et al., 2005), stability in chaotropes (Peretz et al., 2002), and relative antibody binding to unfolded and folded PrP states (Safar et al., 1998). Clinically, the strains vary in brain regions targeted, even within the same species expressing identical $\mathrm{PrP}^{\mathrm{C}}$ molecules (Fraser and Dickinson, 1968, 1973; Bruce et al., 1989). Inhibition of one prion strain by a second strain occurs in select prion strain mixtures (Dickinson et al., 1972; Bartz et al., 2007).

We have previously shown that prion strains can be distinguished in brain sections using conformation-sensitive luminescent conjugated polymers (LCPs) as amyloid-specific ligands (Sigurdson et al., 2007). LCPs contain a flexible polythiophene chain that can freely rotate and lock into a conformation depending on the molecule bound (Nilsson et al., 2003). Hence a specific spectral signature can be achieved from the LCP bound to a distinct molecular target (Nilsson et al., 2004). The LCP spectral profiles have been used to distinguish AL (amyloid light chain), serum AA (amyloid A), and TTR (transthyretin) in human patients (Nilsson et al., 2010), and heterogenic $A \beta$ aggregates in the brains of transgenic mice (Nilsson et al., 2007).

Here we used an anionic LCP, polythiophene acetic acid (PTAA), to investigate whether distinct prion strains interact and change the disease pathogenesis. We inoculated mice with two prion strains having known PTAA emission spectra and tracked the interaction of the $\mathrm{PrP}^{\mathrm{Sc}}$ aggregates at terminal disease. We found that prion strains can exist independently or form hybrid plaques, depending on the combination of prion strains involved. In specific brain regions, a prion strain could serve as a scaffold for a second strain or show an inhibitory effect on the replication of a second strain.

\section{Materials and Methods}

Prion inoculations. Male and female tga20 transgenic mice, which overexpress murine PrP (Fischer et al., 1996), were intracerebrally inoculated into 

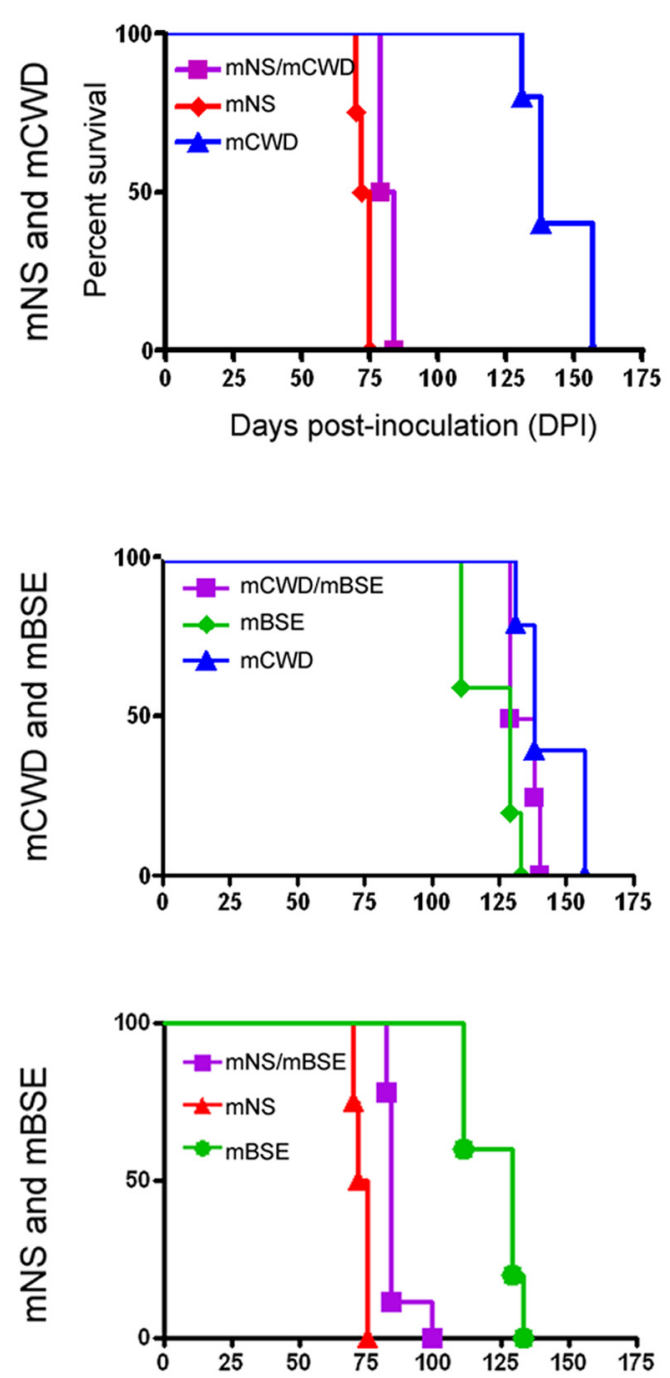

Figure 1. Survival period (left) and brain histopathology (right) of mice inoculated with individual prion strains or a mixture of two strains. For the histopathology, a lesion severity score (spongiform change, astrogliosis, and PrP ${ }^{\text {sc }}$ deposition) was plotted for 10 brain regions (see Materials and Methods). Each ring represents one point. The two individual strains and the mixture are represented by the same color as in the survival plot.

the left parietal cortex with $30 \mu \mathrm{l}$ of $1 \%$ brain homogenate from fourthpassage mouse-adapted chronic wasting disease (mCWD) maintained in tga20 mice that was originally derived from a naturally infected mule deer, second-passage natural sheep scrapie (mNS) in wild-type (WT) mice, or second-passage bovine spongiform encephalopathy (mBSE) in WT mice. Strain development and characterization have been previously described (Sigurdson et al., 2006, 2007). For mixture experiments, strains were mixed 50:50 by volume and inoculated intracerebrally. Mice were monitored every second day, and transmissible spongiform encephalopathy was diagnosed according to clinical criteria including ataxia, kyphosis, stiff tail, and hindleg paresis. Mice were killed at the onset of terminal disease. Mice were maintained under specific pathogen-free conditions, and all experiments were performed in accordance with the animal welfare guidelines of the Kanton of Zurich or the University of California, San Diego.

Western blots. The $10 \%$ brain or spleen homogenates were prepared in PBS using a Ribolyzer. Extracts of 50-90 $\mu \mathrm{g}$ of protein were diluted with a Tris-based buffer (10 mm Tris, $10 \mathrm{~mm}$ EDTA, $100 \mathrm{~mm} \mathrm{NaCl}, 0.5 \%$ $\mathrm{NP}-40$, and $0.5 \%$ deoxycholate) and digested with $100 \mu \mathrm{g} / \mathrm{ml}$ proteinase $\mathrm{K}$ for $30 \mathrm{~min}$ at $37^{\circ} \mathrm{C}$. An LDS (lithium dodecyl sulfate)-based buffer was then added, and the samples were heated to $95^{\circ} \mathrm{C}$ for 5 min before elec- trophoresis through a $12 \%$ Bis-Tris precast gel (Invitrogen), followed by transfer to a nitrocellulose membrane by wet blotting. Proteins were detected with anti-PrP antibody POM1 (epitope in the globular domain, amino acids 121-230) or POM2 (epitope on the octarepeats: amino acids $58-64,66-72,74-80,82$ 88) (Polymenidou et al., 2008). For secondary detection, we used an HRP-conjugated antimouse IgG antibody (Zymed; Invitrogen). Signals were visualized with the ECL detection kit (Pierce).

Histopathology and immunohistochemical stains. Two-micrometer-thick sections were cut onto positively charged silanized glass slides and stained with hematoxylin and eosin, or immunostained using antibodies for PrP (SAF84), astrocytes (GFAP), or microglia (Iba1). For PrP staining, sections were deparaffinized and incubated for $6 \mathrm{~min}$ in $98 \%$ formic acid, and then washed in distilled water for $5 \mathrm{~min}$. Sections were heated to $100^{\circ} \mathrm{C}$ in a pressure cooker in citrate buffer, $\mathrm{pH}$ 6.0, cooled for $3 \mathrm{~min}$, and washed in distilled water for $5 \mathrm{~min}$. Immunohistochemical stains were performed on an automated Nexus staining apparatus (Ventana Medical Systems) using an IVIEW DAB Detection kit (Ventana). After incubation with protease 1 (Ventana) for $16 \mathrm{~min}$, sections were incubated with anti-PrP SAF84 (SPI Bio; 1:200) for $32 \mathrm{~min}$. Sections were counterstained with hematoxylin. GFAP immunohistochemistry for astrocytes (1:1000 for $24 \mathrm{~min}$; Dako) and Ibal (1:2500 for $32 \mathrm{~min}$; Wako Chemicals) for microglia was similarly performed, however, with antigen retrieval by heating to $100^{\circ} \mathrm{C}$ in EDTA buffer, $\mathrm{pH} 8.0$.

Lesion profile. We selected 10 anatomic brain regions in accordance with previous strain typing protocols (Fraser and Dickinson, 1968; Bruce et al., 1991) from three to five mice. We evaluated spongiosis on a scale of $0-5$ (not detectable, rare vacuoles, mild, moderate, severe, and status spongiosus). We scored gliosis and PrP immunological reactivity on a $0-3$ scale (not detectable, mild, moderate, severe). A sum of the three scores resulted in the value obtained for the lesion profile for the individual animal. The "radar plots" depict the scores for spongiform change, gliosis, and PrP deposition. Numbers correspond to the following brain regions: (1) dorsal medulla, (2) cerebellum, (3) hypothalamus, (4) medial thalamus, (5) hippocampus, (6) septum, (7) medial cerebral cortex dorsal to hippocampus, (8) medial cerebral cortex dorsal to septum, (9) white matter at cerebellar peduncles, and (10) white matter at cerebral peduncles. Investigators blinded to animal identification performed histological analyses.

LCP staining of tissue sections. The synthesis of PTAA (mean molecular weight, $3 \mathrm{kDa}$ ) has been reported (Ding et al., 2000; Ho et al., 2002). Frozen mouse brain sections were dried for $1 \mathrm{~h}$ and fixed in $100 \%$ ethanol for $10 \mathrm{~min}$. After washing with deionized water, the sections were equilibrated in the incubation buffer, $100 \mathrm{~mm}$ sodium carbonate at $\mathrm{pH} 10.2$. LCPs were diluted in incubation buffer $(0.01 \mu \mathrm{g} / \mu \mathrm{l})$, added to the brain sections, incubated for $30 \mathrm{~min}$ at room temperature, and washed with incubation buffer.

Fluorescence microscopy. Spectra were collected with a Zeiss Axioplan 2 microscope, fitted with a Spectraview 4.0 (Applied Spectral Imaging) and a Spectra-Cube (interferometrical optical head SD 300) module with cooled CCD camera, through a 405/30 nm (LP 450) or a 470/40 nm (LP 515) bandpass filter. The data were processed with SpectraView 3.0 EXPO. Spectra were collected from 10 individual spots within three to five 
A

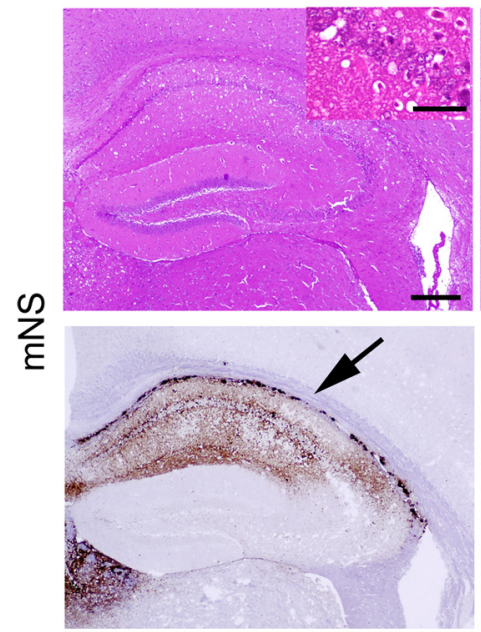

C

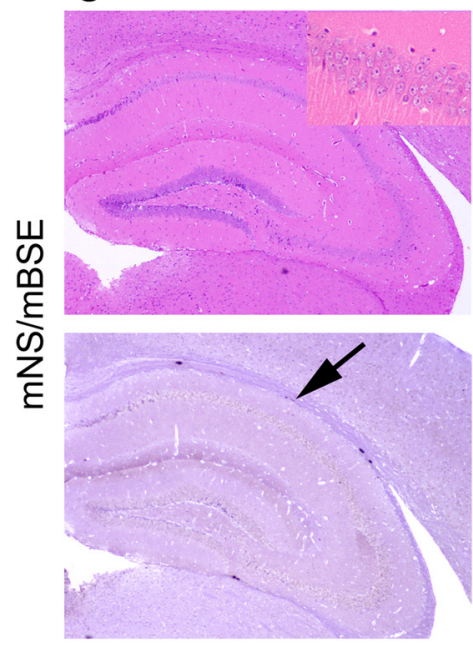

B
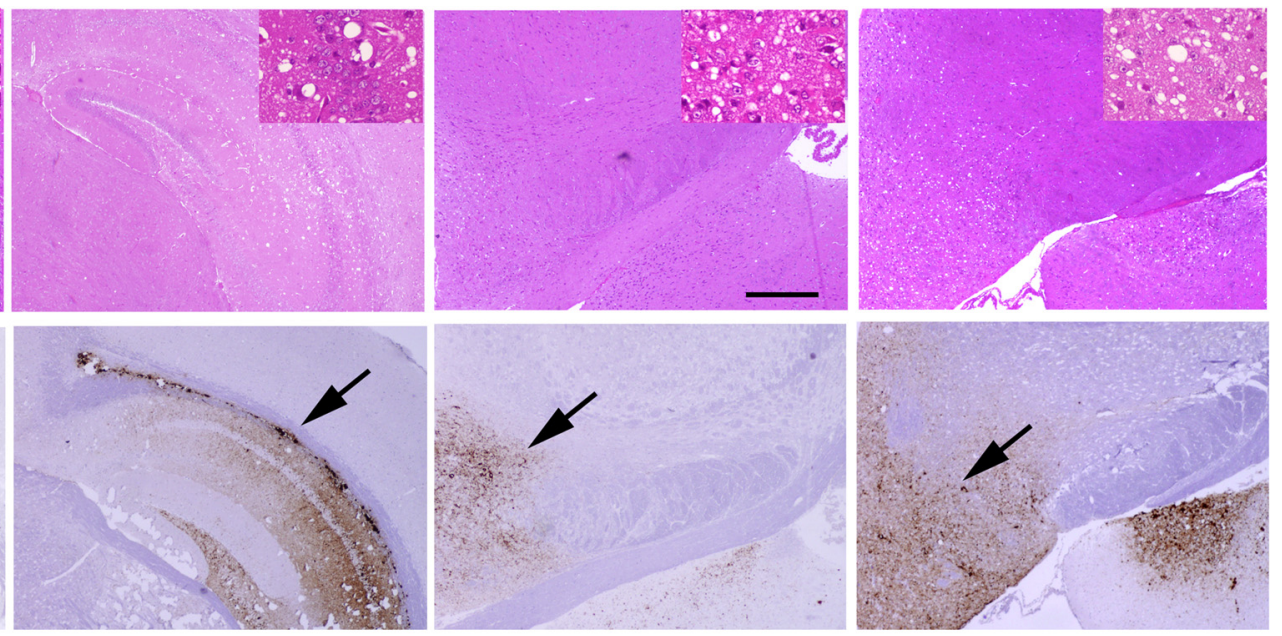

D
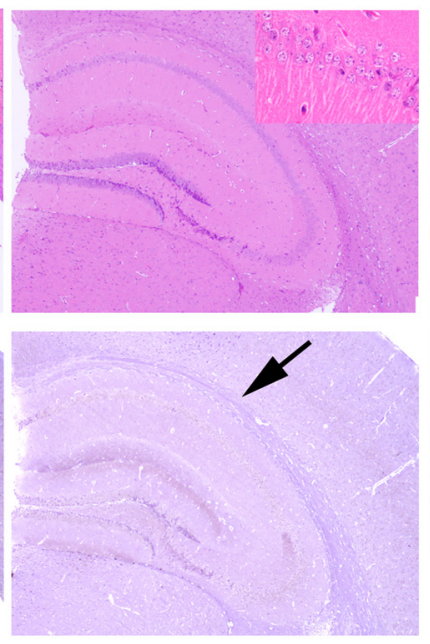
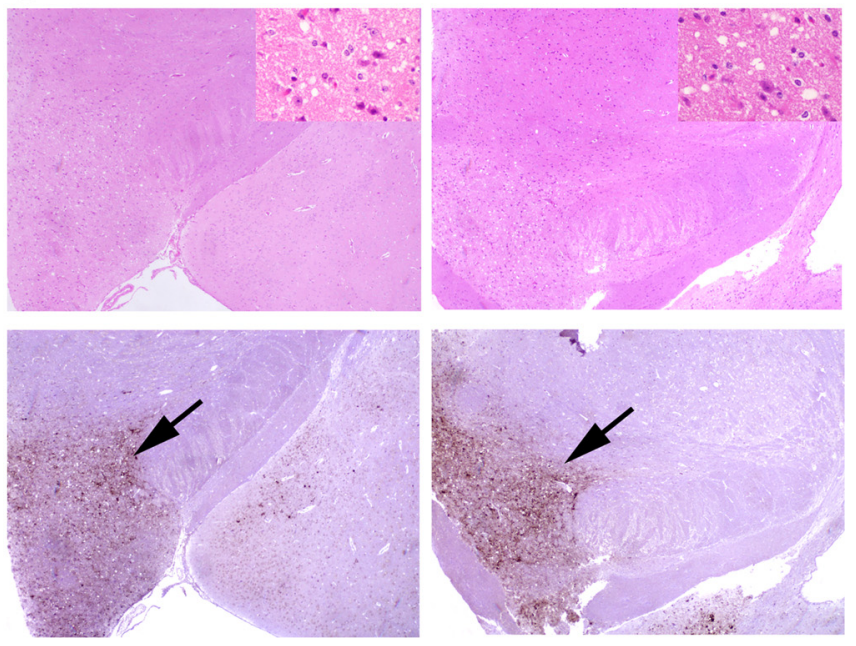

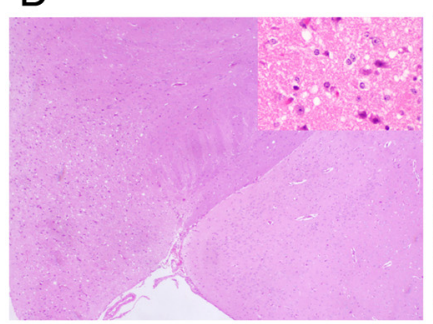

Figure 2. Hippocampal PrP ${ }^{\mathrm{Sc}}$ deposition is markedly reduced in the $\mathrm{mNS} / \mathrm{mBSE}$ strain mixture. Hematoxylin and eosin (HE) (top) and PrP immunohistochemistry (bottom) from mNS and $\mathrm{mNS} / \mathrm{mBSE}$ mixtures. The inset in the HE shows a higher magnification of the spongiform change in the same region. $\boldsymbol{A}-\boldsymbol{D}$, Hippocampus $(\boldsymbol{A})$ and hypothalamus $(\boldsymbol{B})$ of mice infected with $\mathrm{mNS}$ shows the spongiform encephalopathy and $\mathrm{PrP}^{\mathrm{Sc}}$ deposition (arrows) in two representative mice, whereas $\boldsymbol{C}$ and $\boldsymbol{D}$ show the same regions from mice infected with the $\mathrm{mNS} / \mathrm{mBSE}$ mixture. The hippocampus (C), but not the hypothalamus (D), has minimal spongiform change and a lack of PrP ${ }^{S c}$ staining in the mice infected with the $\mathrm{mNS} / \mathrm{mBSE} \mathrm{mixture}$. Scale bars: $\boldsymbol{A}, \boldsymbol{B}, 500 \mu \mathrm{m}$; inset, $100 \mu \mathrm{m}$.

plaques and from unstained regions and mock-inoculated negative control tga20 mice. Fluorescent spectral unmixing was performed using the function in the software to separate the spectral emission signals. Emission spectra selected from distinct aggregates were arbitrarily assigned to red or green pseudocolors, and only pixels with spectral emissions matching that of the selected aggregate were depicted by the software.

Statistical methods. For spectral collection of PTAA bound to prion aggregates, brain sections were analyzed as follows: 10 individual spots within each of three to five plaques from each case were examined, yielding 30-50 measurements per mouse. The fluorescent intensity ratios were calculated (intensity at $532 \mathrm{~nm} /$ emission maximum, and 532/641), and mean and SD were recorded for each spectral ratio for each individual. An unpaired, two-tailed Student $t$ test was performed using mean values of single animals as observations.

\section{Results}

\section{Generation of the strain mixtures}

To investigate whether two prion strains can interact and change the pathogenesis of prion disease, we intracerebrally inoculated brain homogenate containing two distinct prion strains into tga20 mice, which overexpress mouse $\operatorname{PrP}^{\mathrm{C}}$. We used mouseadapted strains of natural sheep scrapie ( $\mathrm{mNS}$ ), bovine spongi- form encephalopathy (mBSE), and chronic wasting disease (mCWD). Each strain mixture consisted of an equal volume of brain homogenate from (1) mNS and mBSE, (2) mNS and mCWD, or (3) mBSE and mCWD. Groups of tga20 mice were inoculated with individual prion strains as controls. The mNSinoculated mice were the first group to develop terminal signs of prion disease, with an average incubation period of $73 \mathrm{~d}$. The mNS mixed with either $\mathrm{mBSE}$ or $\mathrm{mCWD}$ resulted in a significant delay in the incubation period ( 85 and $82 \mathrm{~d}$; log rank test; $p<$ 0.001 and $p=0.002$, respectively) (Fig. 1). For the $\mathrm{mCWD} / \mathrm{mBSE}$ mixture, the incubation period was midway between the individually inoculated strains and was not significantly different from the faster mBSE strain $(p=0.10)$ (Fig. 1). Therefore, two of the three strain mixtures significantly delayed the time to terminal prion disease when compared with the most rapid strain.

\section{Neuropathology of mice infected with the strain mixtures}

To determine whether the lesion distribution changed in mice inoculated with the prion strain mixture, we mapped the location and severity of the spongiform change, gliosis, and $\operatorname{PrP}^{\mathrm{Sc}}$ deposits 
A
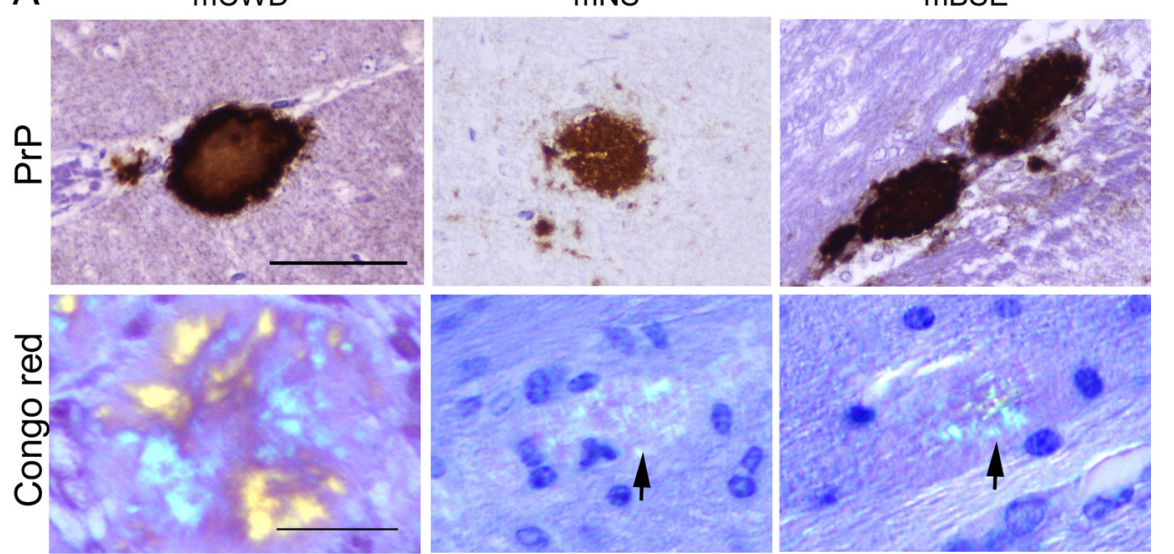

B

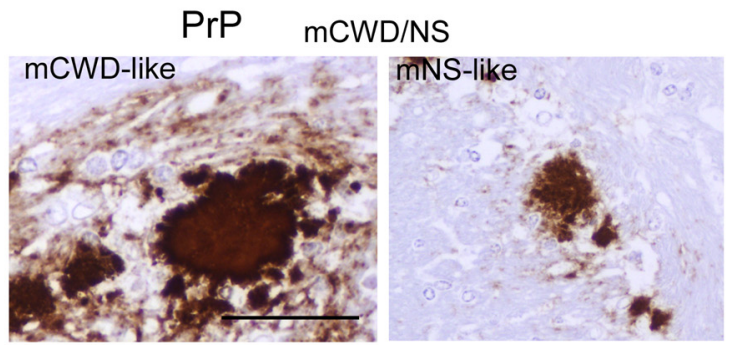

$\mathrm{mCWD} / \mathrm{mBSE}$
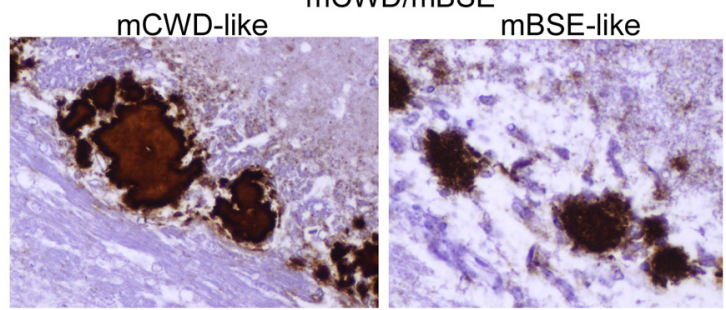

$\mathrm{mNS} / \mathrm{mBSE}$
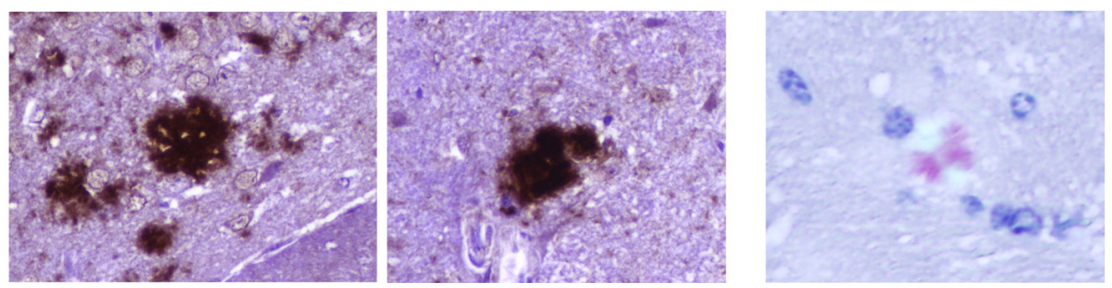

Figure 3. Plaque morphology and Congo red staining properties of the individual prion strains and the mixtures in the brain. $\boldsymbol{A}$, Individual strains. Dense $\mathrm{mCWD}$ plaques are characterized by a dark peripheral border, whereas mNS plaques are lighter staining with an irregular border and $\mathrm{mBSE}$ plaques appear oval and homogenous. All $\mathrm{mCWD}$ plaques and only a small subpopulation of $\mathrm{mNS}$ and $\mathrm{mBSE}$ plaques stain with Congo red. $\boldsymbol{B}$, Mixed strains show plaques of varying morphology reminiscent of the individual strains. The $\mathrm{mNS} / \mathrm{mBSE}$ plaque population appeared as small plaques with irregular contours. Scale bars: $\boldsymbol{A}, \boldsymbol{B}$ (PrP), $100 \mu \mathrm{m} ; \boldsymbol{B}$ (Congo red), $50 \mu \mathrm{m}$.

in 10 brain regions. Although the lesion targets of each strain overlapped, there were also strain-specific targets; for example, mBSE affected the thalamus, mCWD affected the cerebral peduncles, and $\mathrm{mNS}$ affected the hippocampus. In general, mBSE and $\mathrm{mNS}$ targeted similar regions of the brain (Fig. 1).

The impact of the strain mixture on the lesion distribution depended on the strains inoculated. For mice infected with the $\mathrm{mNS} / \mathrm{mCWD}$ mixture, the lesion targets in brain nearly exactly matched those of the single mNS rapid strain, but with an increase in lesion intensity in the dorsal medulla and septum (Fig. 1, regions 1 and 6). In contrast, the $\mathrm{mCWD} / \mathrm{mBSE}$ mixture targeted the combined sites of $\mathrm{mBSE}$ and $\mathrm{mCWD}$, suggesting that the strains were replicating independently. The $\mathrm{mBSE} / \mathrm{mNS}$ mixture generally showed a lesion profile similar to the individual isolates, yet surprisingly, in the hippocampus where the mNS lesions have been severe, the lesions and $\mathrm{PrP}^{\mathrm{Sc}}$ deposition were hardly detectable in the mixture (Figs. 1 , region 5 ; 2) ( $\mathrm{mNS}$ vs $\mathrm{mNS} / \mathrm{mBSE}$, unpaired Student's $t$ test, $p<0.001)$. In other regions, such as the hypothalamus, the $\operatorname{PrP}{ }^{S c}$ deposition was unaffected by the mBSE strain (Fig. 2). These latter results suggest that the mBSE interferes with the mNS accumulation in the hippocampus.

The three individual prion strains induced the formation of morphologically distinct plaques. $\mathrm{mCWD}$ plaques consisted of large (30-100 $\mu \mathrm{m})$, congophilic, circular plaques with a sharp dense border and occurred primarily in the corpus callosum, meningeal vessels, and near the lateral ventricle (Fig. 3). In contrast, $\mathrm{mBSE}$ and $\mathrm{mNS}$ deposits were both composed of abundant diffuse aggregates and rare small congophilic plaques and could not be morphologically distinguished (Fig. 3). For the mixture of $\mathrm{mNS}$ and mCWD, we detected both abundant diffuse aggregates typical of $\mathrm{mNS}$ as well as the large mCWD-like corpus callosum plaques. Thus, although the mNS lesion profile was similar to that of the mNS/ mCWD mixture, the mCWD plaques were clearly present (Fig. 3). The mCWD plaques also occurred in the $\mathrm{mCWD} /$ mBSE mixture (Fig. 3). Therefore, the strains could be distinguished by plaque morphology in the $\mathrm{mCWD} / \mathrm{mBSE}$ and $\mathrm{mNS} / \mathrm{mCWD}$ mixtures, but not in the $\mathrm{mNS} / \mathrm{mBSE}$ mixtures.

\section{Biochemical features of the strain mixtures}

Since we could not identify the individual strains in the mNS/mBSE mixture histologically, we assessed the strain mixture biochemically by the predominant PKresistant $\mathrm{PrP}^{\mathrm{Sc}}$ core size. After $\mathrm{PK}$ digest, mBSE has a much smaller $\operatorname{PrP}^{\mathrm{Sc}}$ core (19 $\mathrm{kDa}$ ) and lacks the N-terminal octapeptide repeats compared with $\mathrm{mNS}$, which has a larger core $(21 \mathrm{kDa})$ that contains the repeats. We digested the $\mathrm{mNS} / \mathrm{mBSE}$-infected brain with $\mathrm{PK}$ and performed Western blots using anti-PrP antibodies POM1 and POM2 that recognize the $\mathrm{C}$ or $\mathrm{N}$ terminus, respectively. Only $\mathrm{mNS}$ is recognized by the POM2 antibody (epitope on the octarepeats: amino acids 58-64, $66-72,74-80,82-88)$. Of nine mice inoculated with $\mathrm{mNS} /$ mBSE, only one mouse had $\operatorname{PrP}^{\mathrm{Sc}}$ compatible with a predominance of the mBSE strain (Fig. 4). Thus, the mNS appeared to prevail in the $\mathrm{mNS} / \mathrm{mBSE}$ mixture by Western blot.

\section{Tracking strains by the LCP emission spectra}

To experimentally test a model in which incompatible strains remain distinct, we tracked the strains in the mixture with our 
recently developed method using PTAA emission spectra. PTAA is an LCP in which the thiophene rings lock into a specific planarity when bound to prion aggregates. On excitation with light emerging through a $470 / 40 \mathrm{~nm}$ bandpass filter, the PTAA emits spectra of light from wavelengths of 500-700 $\mathrm{nm}$ that are of varying intensities, depending on the prion strain bound. PTAA bound to MCWD plaques emits light with a maximum intensity at $\sim 565 \mathrm{~nm}$, whereas PTAA bound to mBSE and $\mathrm{mNS}$ emits light with a maximum intensity at $\sim 595$ and $600 \mathrm{~nm}$, respectively (Fig. 5A,D,E). The shorter wavelength of the emission maxima for PTAA bound to mCWD suggests that the polythiophene backbone is nonplanar and loosely packed, whereas the shift of the emission maxima toward longer wavelengths for mBSE and mNS suggests that the backbone is planar and tightly packed. Nonplanar, separated LCP molecules emit light at 530-540 nm, whereas planar, stacked LCP molecules emit light at $640-650 \mathrm{~nm}$ (Andersson et al., 1997; Berggren et al., 1999; Nilsson et al., 2002). Therefore, we calculated and plotted the ratio of light intensity emitted at 532/emission maximum $\left(R_{532 / \text { Emax }}\right)$ and 532/641 $\left(R_{532 / 641}\right)$ for each prion strain and for the strain mixtures as an indicator of the PTAA conformation (Fig. $5 A, D, E$ ).

We performed PTAA staining of frozen brain sections at the level of hippocampus and thalamus of prion-infected and uninfected mice. PTAA bound to $\mathrm{mNS} / \mathrm{mCWD}$ aggregates showed emission spectra that depended on the plaque location in the brain. The corpus callosum region showed both mCWD-like and mNS-like plaques, whereas plaques in other brain regions displayed PTAA spectral ratios corresponding to mNS (Fig. 5A-C). The mCWD-like plaques emitted green spectra with emission maxima at $\sim 565 \mathrm{~nm}$, whereas the mNS-like plaques exhibited red-shifted PTAA spectra with maxima at $\sim 595 \mathrm{~nm}$ and a distinct shoulder at longer wavelengths $(600-650 \mathrm{~nm})$. Some of the corpus callosum plaques exhibited concentric layers of color, always with a CWD-like core and a mNS-like periphery (Fig. 5C). These laminar plaques were detected only in the corpus callosum, suggesting that the mCWD plaques may serve as a scaffold for the $\mathrm{mNS}$ in this brain region.

In contrast to the $\mathrm{mNS} / \mathrm{mCWD}$ mixture, the PTAA emission spectra for the $\mathrm{mCWD} / \mathrm{mBSE}$ plaques were similar to either that of $\mathrm{mCWD}$ or $\mathrm{mBSE}$, suggesting that the strains remained distinct (Fig. 5D). In the corpus callosum region, we observed only a PTAA spectral profile consistent with $\mathrm{mCWD}$ plaques, whereas plaques in other regions showed a profile consistent with $\mathrm{mBSE}$ (Fig. $5 D, F$ ). The mNS/mBSE aggregates showed emission spectra that were not significantly different from either mNS or mBSE, and could not be distinguished (Fig. $5 E, G$ ).

\section{Second passage of $\mathrm{mNS} / \mathrm{mCWD}$}

$\mathrm{mNS} / \mathrm{mCWD}$ appear to form plaques that contain both strains in the corpus callosum where both the $\mathrm{mNS}$ and $\mathrm{mCWD}$ plaques typically develop. We would expect that, if mCWD merely serves as a scaffold for mNS and that no mixed hybrid fibrils had formed, a second passage should still reveal PTAA spectral properties of the two independent parent strains. However, if the strains produced mixed fibrils, a third novel strain with a distinct PTAA spectral profile might arise on additional passage. To directly test these predictions, we passaged the brain homogenate from the $\mathrm{mNS} / \mathrm{mCWD}$ infection into tga 20 mice. We found that the incubation period, lesion profiles (Fig. 6A,B), and plaque morphology were indistinguishable from the first passage. For the PTAA emission spectra, we again detected an mNS-like spectra emitted from most aggregates, except those at the corpus callosum, which again emitted two different PTAA spectra corresponding to $\mathrm{mCWD}$ or $\mathrm{mNS}$ (Fig. $6 C-E$ ). Similar to the first passage, we also observed hybrid corpus callosum plaques with a spectra consistent with an mCWD-like core and an $\mathrm{mNS}$-like periphery. Thus, the $\mathrm{mNS}$ and $\mathrm{mCWD}$ aggregates appeared to be preserved as distinct entities or form the same laminar plaques on second passage, suggesting that the individual fibrils remain homotypic during plaque formation.

\section{Changing the ratio of $\mathrm{mNS} / \mathrm{mCWD}$}

In comparing the incubation periods, we found that the $\mathrm{mNS}$ strain leads to terminal prion disease more rapidly than the mCWD. Therefore, we next tested whether an increase in the ratio of $\mathrm{mCWD}$ inocula relative to $\mathrm{mNS}$ could affect the incubation period, the lesion profile, or the plaque morphology. A group of mice was inoculated with a mixture consisting of a 10:90 ratio of $\mathrm{mNS}$ and $\mathrm{mCWD}$, respectively. The incubation period for the 10:90 $\mathrm{mNS} / \mathrm{mCWD}$ mixture was significantly longer than that of mice inoculated with the 50:50 mixture (Fig. 6A) ( $p=$ 0.002 ). Consistent with having more mCWD aggregates, the histological lesion profile in every brain region became more mCWD-like (Fig. 6B). Yet, despite the increase in $\mathrm{mCWD}$ in the inoculum, we measured an identical emission profile from the aggregate-bound PTAA, and again we detected distinct mCWDlike and mNS-like plaques or hybrid plaques with a mCWD-like core and a mNS-like periphery in the corpus callosum region of the brain (Fig. $6 F-H$ ). Plaques in other regions of the brain again showed a PTAA spectral profile correlating to mNS. Together, these findings indicate that an increase in mCWD led to an increase in lesions to $\mathrm{mCWD}$-targeted brain regions, but the plaque morphologies and emission spectra were unaffected. 
A
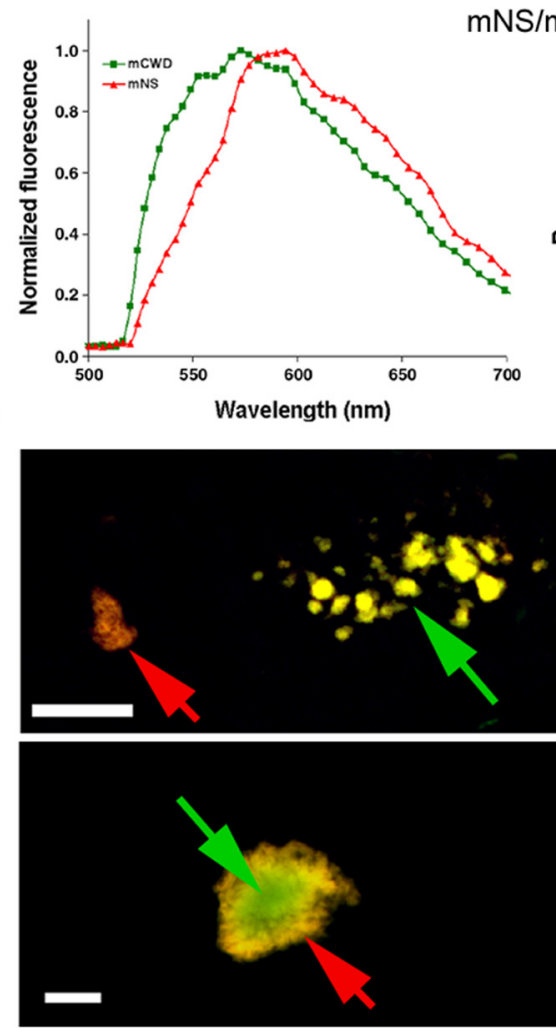

D
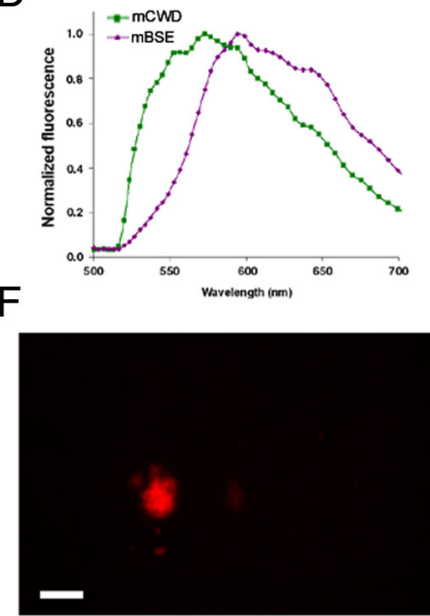

$\mathrm{mNS} / \mathrm{mCWD}$

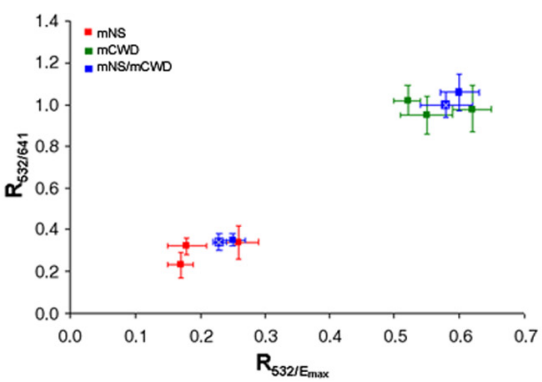

B

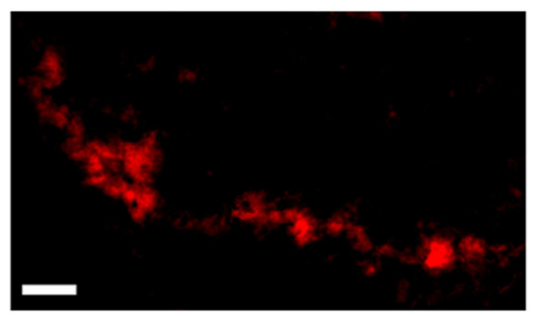

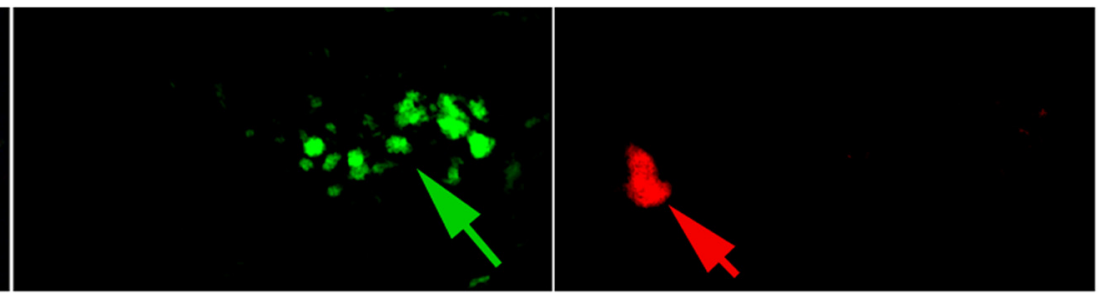
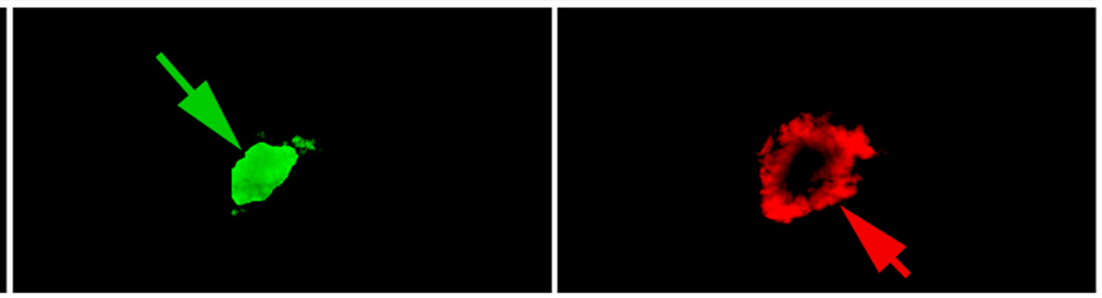

E

$\mathrm{mNS} / \mathrm{mBSE}$
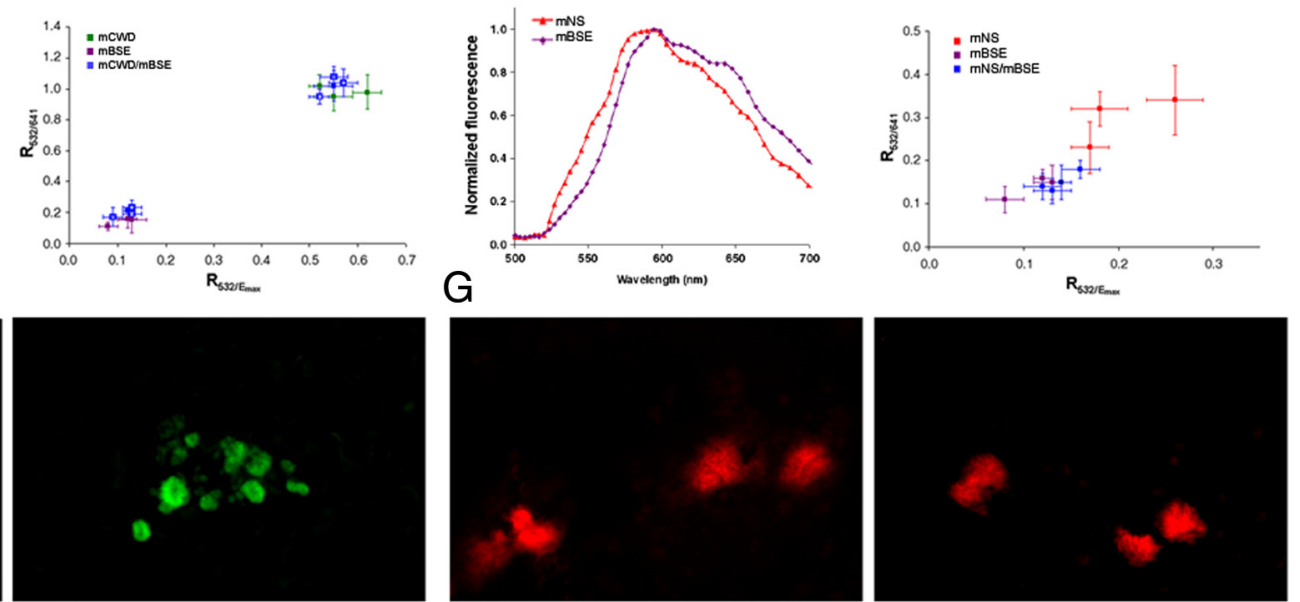

Figure 5. PTAA staining of PrP deposits in single and mixed prion strains in brain cryosections. $A$, Spectra of PTAA bound to $\mathrm{mCWD}$ and mNS plaques (left panel). Correlation diagram of the ratio of light intensity emitted at 532/emission maximum $\left(R_{532 / / \max }\right)$ and 532/641 ( $\left.R_{532 / 641}\right)$ from PTAA bound to $\mathrm{mCWD}$, $\mathrm{mNS}$, or mNS/mCWD plaques in individual mice (right panel). $\boldsymbol{B}, C$, Fluorescence images of PTAA bound to plaques in NS/mCWD-infected mice: a typical mNS plaque (B), and mCWD (yellow) and mNS (yellow-red) plaques (top panel) and hybrid plaques (bottom panel) in the corpus callosum region (C). Middle and right panels, Pseudocolor visualizations of the two distinct types of amyloid deposits after spectral unmixing show pixels that have the same spectrum: PTAA signals are represented in green (mCWD; green spectrum) or red ( $\mathrm{mNS}$; red spectrum). The hybrid plaques have a $\mathrm{mCWD}$ core in green (green arrow) and a mNS border in yellow-red (red arrow) (bottom left).D, E, Spectra (left panel) and correlation diagrams (right panel) of PTAA bound to $\mathrm{mCWD}$ and mBSE plaques (D), and mNS and mBSE plaques (E). $\boldsymbol{F}, \boldsymbol{G}$, Pseudocolor visualization of PTAA bound to $\mathrm{mBSE}$ (red) or $\mathrm{mCWD}$ (green) plaques in the $\mathrm{mCWD} / \mathrm{mBSE}$ mice after spectral unmixing $(\boldsymbol{F})$ and $\mathrm{mBSE}$ (red) or mNS (red) plaques in the $\mathrm{mNS} / \mathrm{mBSE}$ mice $(\boldsymbol{G})$. $\mathrm{mBSE}$ and $\mathrm{mNS}$ show similar spectral profiles. Scale bars: $\boldsymbol{B}, \boldsymbol{C}$ (bottom), $\boldsymbol{F}, 20 \mu \mathrm{m} ; \boldsymbol{C}$ (top), $50 \mu \mathrm{m}$.

\section{Discussion}

\section{Prion strain interactions are highly selective}

Multiple biochemically distinct prion subtypes can cooccur in humans with sporadic CJD (Puoti et al., 1999; Polymenidou et al., 2005; Uro-Coste et al., 2008; Cali et al., 2009). To determine whether the cooccurrence of prion strains changes the disease, here we directly compared individual and mixed strains in mice, histologically and biochemically. Our data show a remarkable selectivity to the interactions between the two strains. The mCWD/
mBSE strains appear to replicate independently, as the aggregate morphology, $\operatorname{PrP}^{S c}$ distribution, and lesion profile revealed the features of each individual strain, and the incubation period was intermediate between the two strains. Consistent with these findings, the emission spectra of PTAA bound to separate PrP aggregates matched that from the singular mCWD or mBSE infections. In contrast, the $\mathrm{mNS} / \mathrm{mCWD}$-inoculated mice developed disease similar to the mNS strain, which was not surprising considering the accelerated disease process caused by the mNS prions. Nev- 
ertheless, the PTAA emission spectra revealed hybrid plaques, as well as the single $\mathrm{mCWD}$ and $\mathrm{mNS}$ plaques. All three plaque populations (hybrid, $\mathrm{mCWD}$, and $\mathrm{mNS}$ ) were maintained on passage. Together, the data indicate that the interaction of prion strains depended on the strains involved.

Our findings are consistent with those recently reported on the coexistence of two prion subtypes in sporadic CJD, in which patients that were methionine homozygous at codon 129 of the human prion gene $(P R N P)$ were classified as either type 1 , type 2 , or a type 1-2 mixture (Cali et al., 2009). The lesion profiles, $\mathrm{PrP}^{\mathrm{Sc}}$ plaque morphology, and biochemical characteristics of the type 1-2 cases revealed the combined phenotypes of both the type 1 and type 2 cases. In the type 1-2 cases, type 1 and type $2 \mathrm{PrP}^{\mathrm{Sc}}$ aggregates were either together in the same anatomic region or were present in separate regions, a finding similar to our results of the cooccurrence of $\mathrm{mNS}$ and $\mathrm{mCWD}$ in the corpus callosum, but not in other regions more permissive for only one strain. Therefore, one strain did not seem to attract a second strain to replicate in a new region. It would be of interest to assess whether the type 1-2 sCJD aggregates directly interact in regions of cooccurrence as we have observed with the $\mathrm{mNS} / \mathrm{mCWD}$ mixture in mice.

Similar to our finding of both independent and hybrid mNS and mCWD plaques, $\alpha$-synuclein and tau can also develop independently or together in patients and in transgenic mice with $\alpha$-synuclein mutations, and can promote the fibrillization of each other in vitro (Giasson et al., 2003). As we have found with prion strains, there is specificity to the interactions since $A \beta$ was not able to induce tau filament formation (Giasson et al., 2003).

\section{mNS/mCWD mixture: scaffold model}

Based on the results with the $\mathrm{mNS} /$ $\mathrm{mCWD}$ mixture in mice, we propose a simplified model in which the early disease stages are characterized by replication of each strain in its preferred target site. Over time, the exponential growth of the rapid mNS strain would lead to a great excess of the mNS compared with the $\mathrm{mCWD}$ strain, enabling the $\mathrm{mNS}$ to populate and expand rapidly from the CWD plaques. The mNS may be exploiting the mCWD fibrils as a polymeric substrate on which to dock and polymerize, which would be consistent with the finding that many proteins, including $\operatorname{PrP}$, fibrillize more efficiently in the presence of a polymer, such as RNA (Deleault et al., 2003, 2005; Calamai et al., 2006).

$\mathrm{E}$

$\mathrm{F}$

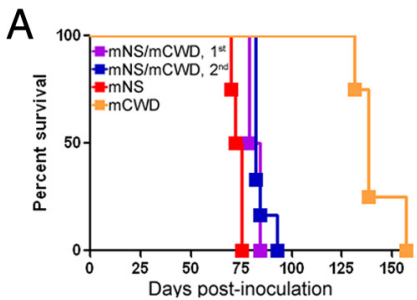

C

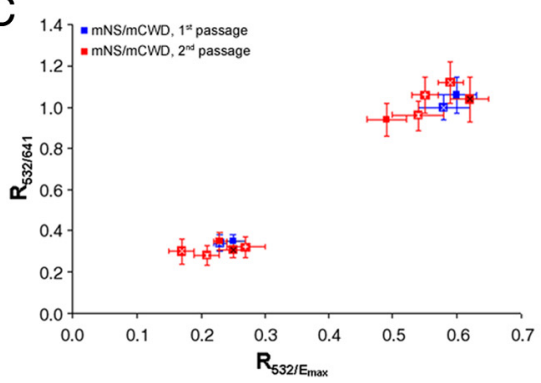

B
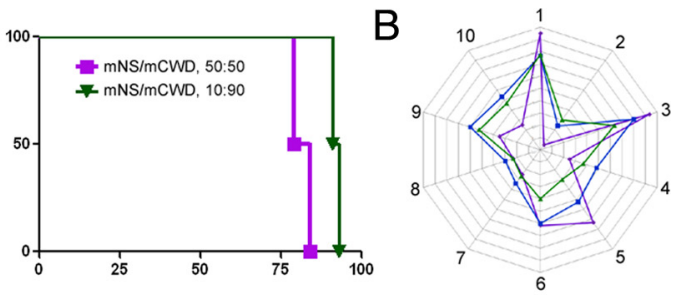

D
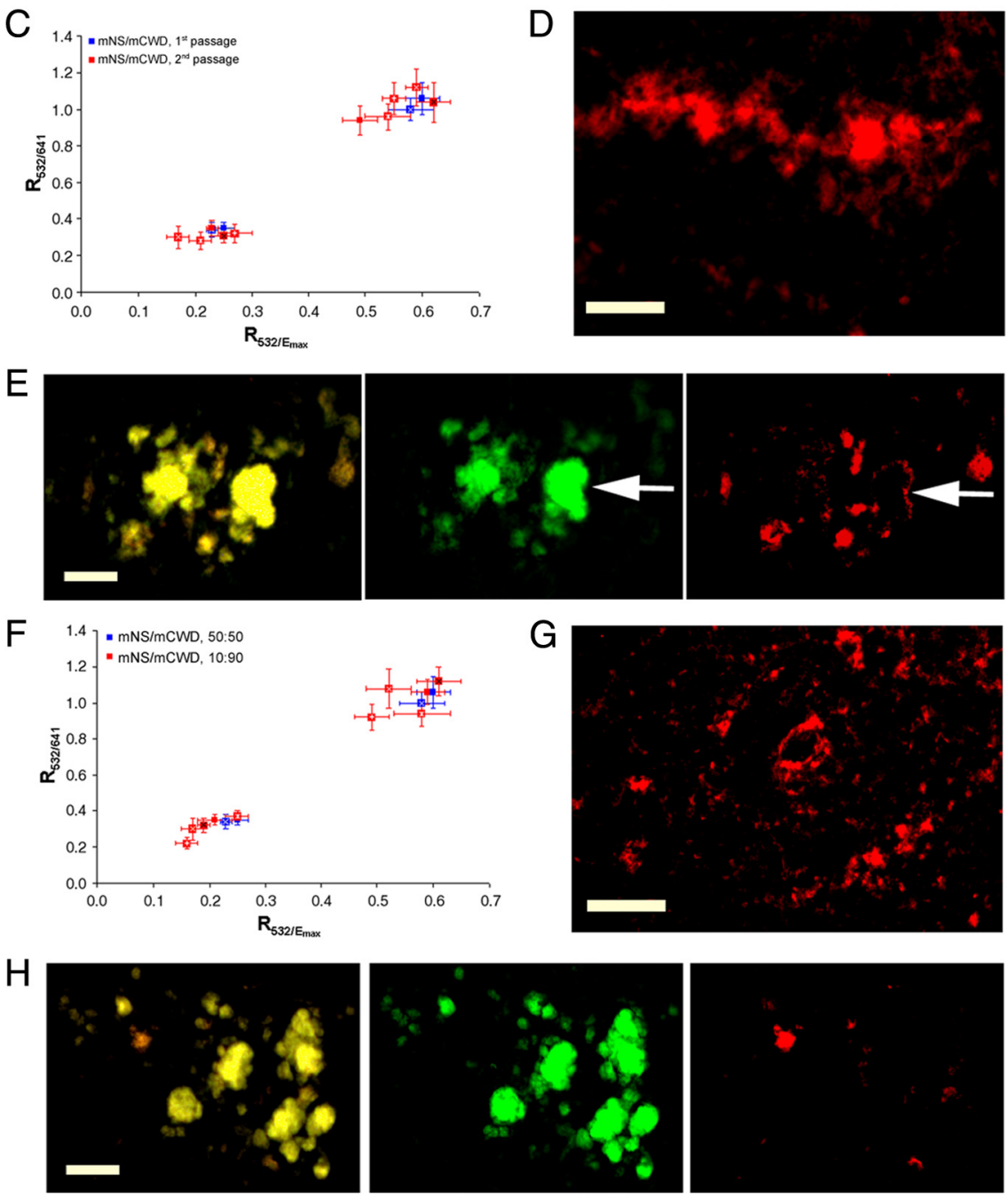

Figure 6. Survival period, brain histopathology, and PTAA spectral profile of mice inoculated with a mixture of mNS and mCWD. A, Comparison of the survival period for first and second passage of mNS/mCWD (left panel) or for the 50:50 or 10:90 mixtures of $\mathrm{mNS} / \mathrm{mCWD}$ (right panel). mNS and mCWD are shown for comparison (left panel). $\boldsymbol{B}$, Lesion severity score (spongiform change, astrogliosis, and $\operatorname{PrP}^{\mathrm{Sc}}$ deposition) plotted for 10 brain regions (see Materials and Methods). Each ring represents one point. The two individual strains and the mixture are represented by the same color as in the survival plot. $C, F$, Correlation diagrams of the ratio of light intensity emitted at 532/emission maximum $\left(R_{532 / \mathrm{Emax}}\right)$ and 532/641 $\left(R_{532 / 641}\right)$ from PTAA bound to $\mathrm{mCWD} / \mathrm{mNS}$ plaques in individual mice from the first and second passage $(\boldsymbol{C})$, and from the 50:50 or 10:90 mNS:mCWD mixture $(\boldsymbol{F})$. $\boldsymbol{D}, \boldsymbol{G}$, Fluorescence image of a typical mNS plaque stained by PTAA. $\boldsymbol{E}, \boldsymbol{H}$, Fluorescence images of PTAA bound to mCWD and mNS plaques in mice inoculated with the second-passage mNS/mCWD $(\boldsymbol{E})$ and with the 10:90 mixture $(\boldsymbol{H})$ (left panels). $\boldsymbol{E}, \boldsymbol{H}$, Pseudocolor visualizations show the two distinct spectra from amyloid deposits after spectral unmixing: PTAA emission spectra are represented in green (mCWD) (middle panel) or red (mNS) (right panel). Scale bars: $\boldsymbol{D}, \boldsymbol{G}, 20 \mu \mathrm{m} ; \boldsymbol{E}, \boldsymbol{H}, 25 \mu \mathrm{m}$.
Fibrillization studies using recombinant yeast prion protein indicate that fibrils elongate by monomer recruitment (Collins et al., 2004) and that individual amyloid fibrils maintain an extremely uniform structure (Come et al., 1993). Our study is consistent with homotypic fibril formation (Duda et al., 2002), in that the second passage of $\mathrm{mNS} / \mathrm{mCWD}$ resulted again in distinct $\mathrm{mCWD}$ or mNS plaques and corpus callosum plaques consisted 
of a mCWD-like core and a mNS-like periphery. Although we cannot obtain molecular resolution of individual fibrils, the PTAA spectral analysis suggests that single-strain mCWD fibrils were acting as a scaffold for mNS, which led to a hybrid plaque.

\section{Change in pathogenesis: $\mathrm{mNS} / \mathrm{mBSE}$ interference in the hippocampus}

The mNS and mBSE strains had similar $\mathrm{PrP}^{\mathrm{Sc}}$ aggregate morphologies and PTAA spectral profiles and could not be easily distinguished. Intriguingly, in the $\mathrm{mNS} / \mathrm{mBSE}$ mixture, prion aggregates were not present in the hippocampus as is typical of the mNS strain, suggesting that either mBSE prevented mNS accumulation specifically in the hippocampus, perhaps because of the formation of mixed aggregates, or that a new strain had formed with a new lesion profile. The latter seems unlikely to occur on first passage with a mixture of the two strains and the $\mathrm{mNS} / \mathrm{mBSE}$ mixture showed a lesion profile similar to the individual isolates. Although the mechanism is unknown, the ability of one strain to delay or block the replication of a second is not unprecedented and has been described for 22A and 22C strains of mouse scrapie (Dickinson et al., 1972, 1975), HY and DY hamster strains of TME (Bartz et al., 2004, 2007), and SY and FU strains of mouseadapted CJD (Manuelidis, 1998; Manuelidis and $\mathrm{Lu}, 2003$ ). The individual strains maintained their biological phenotype within the mixture experiments, suggesting that no heterotypic fibrils or new strains were forming, which is consistent with our findings.

\section{Using LCPs to distinguish prion strains and other proteinopathies}

LCPs provide a useful tool to study protein aggregate interactions in histological sections. Although multiple prion strains have been detected through biochemical methods, a second strain may be concealed in the presence of one that is much more abundant (Polymenidou et al., 2005). Since LCP emission spectra have been shown to distinguish systemic amyloids such as amyloid light chain and transthyretin (Nilsson et al., 2010), this technique may be useful to investigate amyloid interactions in cases in which multiple amyloid proteins coexist. For instance, LCPs may be of use in clarifying the significance of amyloid cross-seeding, in which amyloid composed of one protein can induce the fibrillization of a different protein (Lundmark et al., 2005). A more mechanistic understanding of amyloidogenic protein interactions could be useful in clarifying the risk factors common to protein misfolding and in designing therapeutic strategies to block amyloid formation.

Together, these studies demonstrate that prion strain interactions are highly selective and strain dependent, and may lead to hybrid plaque formation in regions in which both strains typically occur. Here, a second prion strain could delay the disease progression of the most rapid strain. In neurodegenerative diseases, multiple misfolded proteins commonly occur in the same brain region (Duda et al., 2002; Debatin et al., 2008; Ghoshal et al., 2009) and additional studies may help clarify whether hybrid plaques form and how they impact the pathogenesis.

\section{References}

Andersson MR, Berggren M, Olinga T, Hjertberg T, Inganas O, Wennerstrom O (1997) Improved photoluminescence efficiency of films from conjugated polymers. Synth Met 85:1383-1384

Bartz JC, Aiken JM, Bessen RA (2004) Delay in onset of prion disease for the HY strain of transmissible mink encephalopathy as a result of prior peripheral inoculation with the replication-deficient DY strain. J Gen Virol $85: 265-273$

Bartz JC, Kramer ML, Sheehan MH, Hutter JA, Ayers JI, Bessen RA, Kincaid
AE (2007) Prion interference is due to a reduction in strain-specific PrPSc levels. J Virol 81:689-697.

Berggren M, Bergman P, Fagerstrom J, Inganas O, Andersson M, Weman H, Granstrom M, Stafstrom S, Wennerstrom O, Hjertberg T (1999) Controlling inter-chain and intra-chain excitations of a poly(thiophene) derivative in thin films. Chem Phys Lett 304:84-90.

Bessen RA, Marsh RF (1992) Biochemical and physical properties of the prion protein from two strains of the transmissible mink encephalopathy agent. J Virol 66:2096-2101.

Bruce ME, McBride PA, Farquhar CF (1989) Precise targeting of the pathology of the sialoglycoprotein, $\mathrm{PrP}$, and vacuolar degeneration in mouse scrapie. Neurosci Lett 102:1-6.

Bruce ME, McConnell I, Fraser H, Dickinson AG (1991) The disease characteristics of different strains of scrapie in Sinc congenic mouse lines: implications for the nature of the agent and host control of pathogenesis. J Gen Virol 72:595-603.

Calamai M, Kumita JR, Mifsud J, Parrini C, Ramazzotti M, Ramponi G, Taddei N, Chiti F, Dobson CM (2006) Nature and significance of the interactions between amyloid fibrils and biological polyelectrolytes. Biochemistry 45:12806-12815.

Cali I, Castellani R, Alshekhlee A, Cohen Y, Blevins J, Yuan J, Langeveld JP, Parchi P, Safar JG, Zou WQ, Gambetti P (2009) Co-existence of scrapie prion protein types 1 and 2 in sporadic Creutzfeldt-Jakob disease: its effect on the phenotype and prion-type characteristics. Brain 132:2643-2658.

Collins SR, Douglass A, Vale RD, Weissman JS (2004) Mechanism of prion propagation: amyloid growth occurs by monomer addition. PLoS Biol 2:e321.

Come JH, Fraser PE, Lansbury PT Jr (1993) A kinetic model for amyloid formation in the prion diseases: importance of seeding. Proc Natl Acad Sci U S A 90:5959-5963.

Debatin L, Streffer J, Geissen M, Matschke J, Aguzzi A, Glatzel M (2008) Association between deposition of beta-amyloid and pathological prion protein in sporadic Creutzfeldt-Jakob disease. Neurodegener Dis 5:347-354.

Deleault NR, Lucassen RW, Supattapone S (2003) RNA molecules stimulate prion protein conversion. Nature 425:717-720.

Deleault NR, Geoghegan JC, Nishina K, Kascsak R, Williamson RA, Supattapone S (2005) Protease-resistant prion protein amplification reconstituted with partially purified substrates and synthetic polyanions. J Biol Chem 280:26873-26879.

Dickinson AG, Fraser H, Meikle VM, Outram GW (1972) Competition between different scrapie agents in mice. Nat New Biol 237:244-245.

Dickinson AG, Fraser H, McConnell I, Outram GW, Sales DI, Taylor DM (1975) Extraneural competition between different scrapie agents leading to loss of infectivity. Nature 253:556.

Ding L, Jonforsen M, Roman LS, Andersson MR, Inganas O (2000) Photovoltaic cells with a conjugated polyelectrolyte. Synth Met 110:133-140.

Duda JE, Giasson BI, Mabon ME, Miller DC, Golbe LI, Lee VM, Trojanowski JQ (2002) Concurrence of alpha-synuclein and tau brain pathology in the Contursi kindred. Acta Neuropathol 104:7-11.

Fischer M, Rülicke T, Raeber A, Sailer A, Moser M, Oesch B, Brandner S, Aguzzi A, Weissmann C (1996) Prion protein (PrP) with aminoproximal deletions restoring susceptibility of PrP knockout mice to scrapie. EMBO J 15:1255-1264.

Fraser H, Dickinson AG (1968) The sequential development of the brain lesion of scrapie in three strains of mice. J Comp Pathol 78:301-311.

Fraser H, Dickinson AG (1973) Scrapie in mice. Agent-strain differences in the distribution and intensity of grey matter vacuolation. J Comp Pathol 83:29-40.

Ghoshal N, Cali I, Perrin RJ, Josephson SA, Sun N, Gambetti P, Morris JC (2009) Codistribution of amyloid beta plaques and spongiform degeneration in familial Creutzfeldt-Jakob disease with the E200K-129M haplotype. Arch Neurol 66:1240-1246.

Giasson BI, Forman MS, Higuchi M, Golbe LI, Graves CL, Kotzbauer PT, Trojanowski JQ, Lee VM (2003) Initiation and synergistic fibrillization of tau and alpha-synuclein. Science 300:636-640.

Ho HA, Boissinot M, Bergeron MG, Corbeil G, Doré K, Boudreau D, Leclerc M (2002) Colorimetric and fluorometric detection of nucleic acids using cationic polythiophene derivatives. Angew Chem Int Ed Engl 41: $1548-1551$.

Lundmark K, Westermark GT, Olsén A, Westermark P (2005) Protein fibrils in nature can enhance amyloid protein $\mathrm{A}$ amyloidosis in mice: 
cross-seeding as a disease mechanism. Proc Natl Acad Sci U S A 102:6098-6102.

Manuelidis L (1998) Vaccination with an attenuated Creutzfeldt-Jakob disease strain prevents expression of a virulent agent. Proc Natl Acad Sci U S A 95:2520-2525.

Manuelidis L, Lu ZY (2003) Virus-like interference in the latency and prevention of Creutzfeldt-Jakob disease. Proc Natl Acad Sci U S A 100: 5360-5365.

Marui W, Iseki E, Uéda K, Kosaka K (2000) Occurrence of human alphasynuclein immunoreactive neurons with neurofibrillary tangle formation in the limbic areas of patients with Alzheimer's disease. J Neurol Sci 174:81-84.

Masliah E, Rockenstein E, Veinbergs I, Sagara Y, Mallory M, Hashimoto M, Mucke L (2001) $\beta$-Amyloid peptides enhance $\alpha$-synuclein accumulation and neuronal deficits in a transgenic mouse model linking Alzheimer's disease and Parkinson's disease. Proc Natl Acad Sci U S A 98: 12245-12250.

Morales R, Estrada LD, Diaz-Espinoza R, Morales-Scheihing D, Jara MC, Castilla J, Soto C (2010) Molecular cross talk between misfolded proteins in animal models of Alzheimer's and prion diseases. J Neurosci 30:4528-4535.

Muramoto T, Kitamoto T, Koga H, Tateishi J (1992) The coexistence of Alzheimer's disease and Creutzfeldt-Jakob disease in a patient with dementia of long duration. Acta Neuropathol Berl 84:686-689.

Nilsson KP, Andersson MR, Inganas O (2002) Conformational transitions of a free amino-acid-functionalized polythiophene induced by different buffer systems. J Phys Condens Matter 14:10011-10020.

Nilsson KP, Rydberg J, Baltzer L, Inganäs O (2003) Self-assembly of synthetic peptides control conformation and optical properties of a zwitterionic polythiophene derivative. Proc Natl Acad Sci U S A 100: 10170-10174.

Nilsson KP, Rydberg J, Baltzer L, Inganäs O (2004) Twisting macromolecular chains: self-assembly of a chiral supermolecule from nonchiral polythiophene polyanions and random-coil synthetic peptides. Proc Natl Acad Sci U S A 101:11197-11202.

Nilsson KP, Aslund A, Berg I, Nyström S, Konradsson P, Herland A, Inganäs O, Stabo-Eeg F, Lindgren M, Westermark GT, Lannfelt L, Nilsson LN, Hammarström P (2007) Imaging distinct conformational states of amyloid-beta fibrils in Alzheimer's disease using novel luminescent probes. ACS Chem Biol 2:553-560.

Nilsson KP, Ikenberg K, Aslund A, Fransson S, Konradsson P, Röcken C, Moch H, Aguzzi A (2010) Structural typing of systemic amyloidoses by luminescent-conjugated polymer spectroscopy. Am J Pathol 176: $563-574$.

Peretz D, Williamson RA, Legname G, Matsunaga Y, Vergara J, Burton DR,
DeArmond SJ, Prusiner SB, Scott MR (2002) A change in the conformation of prions accompanies the emergence of a new prion strain. Neuron 34:921-932.

Polymenidou M, Stoeck K, Glatzel M, Vey M, Bellon A, Aguzzi A (2005) Coexistence of multiple PrPSc types in individuals with Creutzfeldt-Jakob disease. Lancet Neurol 4:805-814.

Polymenidou M, Moos R, Scott M, Sigurdson C, Shi YZ, Yajima B, HafnerBratkovic I, Jerala R, Hornemann S, Wuthrich K, Bellon A, Vey M, Garen G, James MN, Kav N, Aguzzi A (2008) The POM monoclonals: a comprehensive set of antibodies to non-overlapping prion protein epitopes. PLoS ONE 3:e3872.

Prusiner SB (1982) Novel proteinaceous infectious particles cause scrapie. Science 216:136-144.

Puoti G, Giaccone G, Rossi G, Canciani B, Bugiani O, Tagliavini F (1999) Sporadic Creutzfeldt-Jakob disease: co-occurrence of different types of $\operatorname{PrP}(\mathrm{Sc})$ in the same brain. Neurology 53:2173-2176.

Safar J, Wille H, Itri V, Groth D, Serban H, Torchia M, Cohen FE, Prusiner SB (1998) Eight prion strains have $\operatorname{PrP}^{\mathrm{Sc}}$ molecules with different conformations. Nat Med 4:1157-1165.

Schmidt ML, Martin JA, Lee VM, Trojanowski JQ (1996) Convergence of Lewy bodies and neurofibrillary tangles in amygdala neurons of Alzheimer's disease and Lewy body disorders. Acta Neuropathol 91:475-481.

Selikhova M, Williams DR, Kempster PA, Holton JL, Revesz T, Lees AJ (2009) A clinico-pathological study of subtypes in Parkinson's disease. Brain 132:2947-2957.

Sigurdson CJ, Manco G, Schwarz P, Liberski P, Hoover EA, Hornemann S, Polymenidou M, Miller MW, Glatzel M, Aguzzi A (2006) Strain fidelity of chronic wasting disease upon murine adaptation. J Virol 80:1230312311.

Sigurdson CJ, Nilsson KP, Hornemann S, Manco G, Polymenidou M, Schwarz P, Leclerc M, Hammarström P, Wüthrich K, Aguzzi A (2007) Prion strain discrimination using luminescent conjugated polymers. Nat Methods 4:1023-1030.

Small SA, Duff K (2008) Linking Abeta and tau in late-onset Alzheimer's disease: a dual pathway hypothesis. Neuron 60:534-542.

Tsigelny IF, Crews L, Desplats P, Shaked GM, Sharikov Y, Mizuno H, Spencer B, Rockenstein E, Trejo M, Platoshyn O, Yuan JX, Masliah E (2008) Mechanisms of hybrid oligomer formation in the pathogenesis of combined Alzheimer's and Parkinson's diseases. PLoS One 3:e3135.

Uro-Coste E, Cassard H, Simon S, Lugan S, Bilheude JM, Perret-Liaudet A, Ironside JW, Haik S, Basset-Leobon C, Lacroux C, Peoch K, Streichenberger N, Langeveld J, Head MW, Grassi J, Hauw JJ, Schelcher F, Delisle MB, Andreoletti O (2008) Beyond PrP res type 1/type 2 dichotomy in Creutzfeldt-Jakob disease. PLoS Pathog 4:e1000029. 